\title{
ESTRATÉGIAS PEDAGÓGICAS QUE NORTEIAM A PRÁTICA DE ENFERMEIROS PROFESSORES: INTERFACES COM A EDUCAÇÃO LIBERTADORA DE PAULO FREIRE
}

STRATEGIES EDUCATIONAL THAT GUIDE NURSES PRACTICE TEACHERS:

INTERFACES WITH THE LIBERATING EDUCATION OF PAULO FREIRE

Carine Vendruscolo ${ }^{1}$

Daiana Kloh ${ }^{2}$

Alcione Pozzebon ${ }^{3}$

Elisangela Argenta Zanatta ${ }^{4}$

Jean Wilian Bender ${ }^{5}$

Denise Antunes de Azambuja Zocche ${ }^{6}$

Josiane Rodrigues França ${ }^{7}$

1 Enfermeira. Doutora em Enfermagem. Professora Adjunta da graduação e Mestrado Profissional em Enfermagem na Atenção Primária à Saúde da Universidade do Estado de Santa Catarina - UDESC. Diretora de Pesquisa da ABEn SC. Rua Mato Grosso, 545 E, Jardim Itália, Chapecó, SC - Brasil, CEP: 89814-080. E-mail: carine.vendruscolo@udesc.br

2 Enfermeira. Doutora em Enfermagem. Professora do Departamento de Enfermagem da Universidade Federal do Paraná (UFPR). Curitiba, PR - Brasil.

${ }^{3}$ Enfermeira egressa do curso de Enfermagem da Universidade do Estado de Santa Catarina - UDESC. Chapecó, SC - Brasil.

4 Enfermeira. Doutora em Enfermagem. Professora Adjunta da graduação e Mestrado Profissional em Enfermagem na Atenção Primária à Saúde da UDESC. Chapecó, SC - Brasil.

${ }^{5}$ Academico do curso de Enfermagem da Universidade do Estado de Santa Catarina - UDESC. Chapecó, SC - Brasil.

6 Enfermeira. Doutora em Enfermagem. Professora Adjunta da graduação e Mestrado Profissional em Enfermagem na Atenção Primária à Saúde da UDESC. Chapecó, SC - Brasil. 
Artigo Original

Gestão em Saúde

7 Egressa do curso de Enfermagem da UDESC. Chapecó, SC - Brasil. 


\section{RESUMO}

A presente pesquisa visa analisar as estratégias pedagógicas e avaliativas utilizadas pelo enfermeiro professor em cursos de graduação em enfermagem. Estudo descritivo e exploratório com abordagem qualitativa, realizado com 10 enfermeirosprofessores de duas Instituições de Ensino Superior do Estado de Santa Catarina, Brasil. A produção e registro das informações ocorreu entre os meses de fevereiro e junho de 2015, por meio de entrevistas semi-estruturadas, e a análise pautou-se na obra do educador Paulo Freire. Os participantes foram selecionados por amostragem não probabilística, do tipo bola de neve. As questões éticas foram respeitadas mediante parecer favorável do Comitê de Ética em Pesquisas. Observou-se que as estratégias pedagógicas que norteiam as práticas dos enfermeiros professores estimulam o diálogo, a formação de sujeitos críticos, autocríticos e reflexivos. O processo avaliativo, via de regra, ocorre de maneira processual e segue a mesma tendência. Os docentes enfermeiros estão gradativamente, assumindo a tendência pedagógica libertadora, com estratégias distintas voltadas a realidade do educando. Concluiu-se que os professores demonstram a sua preocupação com esse ser enfermeiro em formação, mediante a utilização de metodologias de ensino e avaliação processuais e centradas em suas experiências praticas.

Descritores: Praticas pedagógicas, Ensino, Enfermagem, Serviços de integração docente assistencial.

\section{ABSTRACT}

The present research aims to analyze the pedagogical and evaluative strategies used by the nurse professor in undergraduate courses in nursing. A descriptive and exploratory study with a qualitative approach, carried out with 10 nurse-teachers from two Higher Education Institutions of the State of Santa Catarina, Brazil. The production and recording of information occurred between February and June 2015, through semi-structured interviews, and the analysis was based on the work of educator Paulo Freire. Participants were selected by non-probabilistic, snowball type sampling. The ethical issues were respected through a favorable opinion of the 
Research Ethics Committee. It was observed that the pedagogical strategies that guide the practices of the teacher nurses stimulate the dialogue, the formation of critical, self-critical and reflexive subjects. The evaluation process, as a rule, occurs in a procedural way and follows the same trend. Nursing teachers are gradually assuming the pedagogical liberating tendency, with distinct strategies focused on the reality of the learner. It was concluded that the teachers demonstrate their concern with this nurse being in training, through the use of methodologies of teaching and evaluation processes and focused on their practical experiences.

Descriptores: Pedagogical practices, Teaching, Nursing, Teaching care integration services.

\section{INTRODUÇÃO}

O ideário da aprendizagem autêntica, como prática da liberdade e respeito à autonomia, tem a ver com a tomada de consciência do mundo, por meio da percepção e reflexão sobre as diferentes formas de ver e entender a realidade, os diferentes tipos de saber e, sobretudo, o valor de cada sujeito ${ }^{1}$. O principal desafio da educação é preparar um profissional com conhecimentos teóricos e práticos para enfrentar as dificuldades cotidianas do processo de trabalho².

O educador Paulo Freire acreditava que os seres humanos se tornam sujeitos sociais, críticos e reflexivos por meio da práxis, união homogênea entre a ação e reflexão sobre o mundo. Nesse movimento, homens e mulheres percebem-se como seres sociais e tomam consciência do seu papel, mediante a possibilidade de transformar o mundo vivenciando a práxis ${ }^{1,3}$. Cientes da sua condição de seres inacabados, os seres humanos tornam-se éticos e percebem que "os homens se educam entre si, mediatizados pelo mundo" 1:95. A práxis torna os sujeitos capazes de agir de forma consciente sobre a realidade, pois a ação-reflexão contribui para tal revelação, mediada pelo diálogo e pelas relações construídas no interior das estruturas histórico-sociais ${ }^{3}$.

Nessa perspectiva, as Diretrizes Curriculares Nacionais (DCNs) para a área da saúde, aprovadas em 2001 e atualmente em revisão, orientam a formação de profissionais generalistas, humanistas, críticos e reflexivos, capazes de intervir sobre 
problemas reais, com responsabilidade social e compromisso com a cidadania. A enfermagem, coerente com tal proposito, deve desenvolver competências de: comunicação, liderança, tomada de decisões e gerenciamento, habilidades que devem ser promovidas e fortalecidas não apenas na formação, mas como processo de educação permanente, a partir das demandas da atuação profissional ${ }^{5}$.

Nesse contexto, o papel do professor é fundamental, atuando como facilitador do processo de formação, ao auxiliar os estudantes na construção do conhecimento, fomentando o desenvolvimento como cidadão e como ser humano ${ }^{1}$. O professor/educador precisa incorporar o habito da reflexão na sua prática cotidiana ${ }^{5}$, buscar constante aperfeiçoamento e preocupar-se com a própria formação de maneira contínua. Soma-se a isso a necessidade de que o educando seja protagonista do processo de formação, desenvolvendo habilidades que o permitam ser sujeito desse processo, observador inerente e produtor dos encontros e desencontros que são proporcionados durante a vivência acadêmica. ${ }^{2}$

Destarte, ao tornar-se um mediador no processo de produção do conhecimento, o professor se transforma em um agente de informação, mediante a apropriação do conhecimento a ser discutido e a habilidade didático-pedagógica, articulando o conteúdo programático com a realidade encontrada nos cenários teóricos ou práticos do mundo acadêmico. Cabe ao professor facilitar ao sujeito em formação desenvolver e mostrar suas habilidades, potencialidades e saberes, ajudando-o a crescer dentro do seu ritmo, propiciando a autonomia. ${ }^{6,7}$

No percurso acadêmico, são diversas as metodologias utilizadas por professores para realizar a construção e avaliação do itinerário formativo. $\mathrm{Na}$ área da saúde, refletir a forma como professores de uma Instituição de Ensino Superior instrumentalizam e avaliam seus alunos contribui, não só com o levantamento de informações, mas sobretudo, com a melhoria desse processo, repercutindo, inclusive, na qualidade da atenção no âmbito do Sistema Único de Saúde (SUS).

Muitos educadores julgam os educandos com base em critérios puramente subjetivos e que não são totalmente conhecidos pelo próprio professor que o elabora. Nessa perspectiva, as instituições formadoras buscam possibilidades de avaliação mais democráticas, justas e qualitativas. No entanto, encontram resistência por parte da sociedade, no que se refere a avaliação nos sistemas 
educacionais, pois se acredita que tais iniciativas não assegurariam um ensino de qualidade. $^{8}$

Com o crescente número de profissionais da área aptos para o mercado de trabalho, reitera-se a necessidade de um estudo para conhecer 0 ideário e o posicionamento crítico dos professores da área, neste caso da enfermagem, sobre o processo de formação. Isso implica a realização de investigações quanto a percepção dos atores desse processo, fazendo-os refletir sobre sua atuação como docentes, estudantes ou gestores, no âmbito do ensino e dos serviços. O presente estudo objetiva analisar as estratégias pedagógicas e avaliativas utilizadas pelo enfermeiro professor em cursos de graduação em enfermagem. Sua relevância resulta de temas significativos e atuais para o exercício da docência em enfermagem, considerando que o professor enfermeiro precisa ter conhecimentos específicos na área, mas também compreender o processo educativo, donde a avaliação do educando prevalece como recurso essencial para dar uma ideia da qualidade da formação que está proporcionando.

\section{MÉTODO}

Pesquisa de natureza qualitativa, com abordagem descritiva e exploratória. Os participantes foram 10 enfermeiros professores de duas IES públicas com cursos de graduação em enfermagem, em Santa Catarina. Foram critérios de inclusão dos participantes: ser enfermeiro-professor; ter, no mínimo, cinco anos de docência em enfermagem, sendo pelo menos, um ano em uma das IES estudadas.

A produção e registro das informações ocorreu entre os meses de fevereiro e junho de 2015, por meio de entrevistas semi-estruturadas em local pré-determinado pelo entrevistado, ou sugerido pelo entrevistador. As questões foram voltadas às percepções e atitudes profissionais dos enfermeiros professores, com vistas à análise de sua atuação como professor em sala de aula (teoria) e nos campos de estagio (pratica). As entrevistas foram gravadas e transcritas, após livre consentimento dos participantes.

Os participantes foram selecionados por amostragem não probabilística, do tipo bola de neve. Em cada uma das instituições selecionadas para o estudo, 
solicitou-se que, ao final de suas entrevistas, indicassem outros participantes com as características necessárias à pesquisa. Não foi pré-determinado o número de participantes, de forma que o encerramento da coleta de dados ocorreu mediante repetição dos dados.

Todos os entrevistados possuem mestrado, dois possuem doutorado e três possuem licenciatura. Os demais obtiveram a qualificação pedagógica mediante disciplina do mestrado ou doutorado, por meio de qualificações que as instituições de origem propiciaram, ou ainda, pela própria percepção da necessidade de preparar-se para a atuação como professor, por meio de uma qualificação pedagógica, a fim de fortalecer as práticas didáticas.

Como técnica para tratamento das informações, foi utilizada a proposta operativa para análise de dados qualitativos que consiste em três etapas: a préanálise dos dados brutos, marcada pela seleção e organização dos dados; a exploração do material, codificando os dados brutos em busca alcançar o núcleo da compreensão do texto; e o tratamento dos resultados obtidos e interpretação. ${ }^{9}$ Utilizou-se como marco teórico-filosófico as obras do educador e cientista social Paulo Freire.

A pesquisa seguiu a Resolução 466/2012 do Conselho Nacional de Saúde, sendo aprovada pelo Comitê de Ética em Pesquisa da Universidade Estadual de Santa Catarina, sob parecer número 953.083. Para garantir o anonimato as IES não foram identificadas e os participantes, identificados como Professor 1, Professor $2 \mathrm{e}$ assim, sucessivamente.

\section{RESULTADOS}

A seguir apresentamos as categorias que compuseram os resultados:

\section{Estratégias pedagógicas utilizadas por enfermeiros professores}

As estratégias pedagógicas utilizadas pelos enfermeiros professores são diversificadas, como identificado nos seus discursos: [...]eu não gosto muito de slides, eu uso alguma coisa de aula expositiva, geralmente dinâmicas que envolvam 
um grupo, de integração, estudos dirigidos, geralmente eu passo prévias leituras para aprofundamento, não gosto muito de prova [...](Professor 1).

Observa-se uma preocupação com o conhecimento prévio dos educandos sobre determinada temática, bem como da assimilação do saber, de maneira processual: [...] parto do conhecimento dos estudantes, do reconhecimento dos mesmos, retomando de uma aula para outra buscando sempre relembrar o que a gente estudou na aula anterior (Professor 2).

A aula do tipo expositiva dialogada é citada inúmeras vezes durante as entrevistas, permitindo supor que ainda é a metodologia mais utilizada. Nesse sentido, a enfermeira professora se preocupa com a participação dos educandos em sala. Em seu argumento, alerta para que [...] o conteúdo expositivo seja permeado pela participação dos estudantes, que eles falem, que eles perguntem, que eles critiquem, que eles participem da aula (Professor 3). Para ela, essa atitude tem como objetivo, principalmente, atender os educandos que acabam se distraindo durante a aula, ou aqueles que têm mais dificuldade.

Outra educadora refere que sua prática é voltada a problematização, seguindo a concepção do educador Paulo Freire. Segundo ela, as perguntas precisam ser "instigantes", levando os educandos à "sede do saber", no intuito de [...]tentar fazer com que o aluno busque as respostas [...] (Professor 2). Na mesma lógica, uma estratégia utilizada para instigar o educando, consiste em buscar dados estatísticos e epidemiológicos do SUS, no município em que reside: [...] buscam os dados, constroem num papel, desenham toda essa realidade, olham para esse local e planejam, hipoteticamente, o que se faria nesse município, depois da prática a gente faz isso na vida real com os espaços da prática [...](Professor 4). A educadora ainda destaca que leva seus educandos a fazer visitas a certos territórios, a fim de realizarem um levantamento, através de informações da Unidade de Saúde, sobre as condições de saúde daquela população. Posteriormente, realizam atividades educativas com os usuários da rede de Atenção Primaria, as quais estimulam a conscientização, além de desenvolverem ações de prevenção de doenças e promoção da saúde da comunidade.

Destaca-se, ainda, a preocupação dos educadores enfermeiros com a integração ensino-serviço, de acordo com o preconizado pelas Diretrizes 
Curriculares e políticas de saúde e educação vigentes, já que o SUS atende à prerrogativa constitucional que atribui a ele a ordenação de recursos humanos na área da saúde: [...] os alunos têm que pedir licença para realizar as práticas mas, quando permitem, acabam sendo influenciados pelos profissionais. Eu acho que assim [integrando com o serviço] a gente forma militantes pelo SUS, e não simplesmente, profissionais de saúde [...] (Professor 5).

Outra estratégia importante destacada por um docente foi a socialização das experiências vivenciadas durante o período de atividades teórico-práticas: [...] por exemplo, no centro cirúrgico, no primeiro dia, eu faço a apresentação da unidade, mostro as áreas, os equipamentos, a organização da parte gerencial, para que os alunos consigam se localizar; então no segundo dia eu já começo distribuir os alunos nas salas, alguns em sala de recuperação, outros em sala cirúrgica, desde fazer a recepção do paciente, acompanhar os registros, e no final de cada turno de atividades práticas, a gente faz a socialização [...] (Professor 6).

No contexto das atividades teórico-práticas, os professores destacam dificuldades, como por exemplo, a carga horária reduzida para o desenvolvimento das atividades práticas realizadas nos serviços de saúde, situação que dificulta 0 vínculo e acompanhamento do usuário. Isso, além de dificultar o aprendizado, dificulta a avaliação do educando: [...] a carga horária do curso é pequena, e muitas vezes o aluno vai para campo poucos dias, ele vai muitas vezes cinco dias em um serviço e cinco no outro, ele não consegue muitas vezes estabelecer vínculo com o usuário (Professor 2).

As necessidades do educando também foram mencionadas como algo importante pois permitem ao docente observar o que ainda precisa ser reforçado no campo teórico e/ou pratico, e voltar-se para as suas especificidades enquanto ser humano e ser histórico: [...] eu procuro ser sensível para o tempo dele [educando], para o espaço dele, para as necessidades dele, para as expectativas que ele tem [...] além disso, eu procuro sempre instigar, fazer mais perguntas do que respostas, por que eu vejo que o sujeito que sabe ser e aquele que aprende a aprender [...] (Professor 3). O Professor 5 lembra ainda, a necessidade de os momentos de formação serem algo prazeroso para os educandos: [...] se eles [momentos de aprendizagem] não forem prazerosos, não faz muito sentido você fazer isso, você 
não tem porque terminar [graduação], com sofrimento, não fez muito sentido nisso [...].(Professor 5).

Ainda na perspectiva de resgatar as prerrogativas que fazem parte das DCNs, o professor complementa sua fala no sentido do reconhecimento das competências do futuro profissional de enfermagem, segundo o documento, tanto em relação as praticas pedagógicas quanto na avaliação do estudante: [...] a gente trabalha as competências o tempo todo, eu abordo isso no material de mídia, eu abordo isso na minha fala e eu abordo isso depois do estágio curricular supervisionado, em que $o$ próprio instrumento de avaliação da fase esta voltado para as competências [...] Eu também avalio, encima das competências, porque os nossos instrumentos de avaliação valorizam as competências ditas pelas DCN, essas específicas[...] (Professor 3). O Professor 2 reconhece que muitos educadores reproduzem em suas aulas aquilo que vivenciaram em sua formação e que os eixos que orientam as DCNs contribuem para a formação profissional e também na constituição do ser humano, manifestados em seu modo de viver: [...] eu vivenciei isso na minha graduação. Então esse aprender a ser, aprender a conviver, eles entram no seu modo de viver [...].

\section{A avaliação dos processos de aprendizagem na enfermagem}

Os professores foram abordados em relação as estratégias para a avaliação dos estudantes. Foi mencionado que a avaliação do ensino-aprendizagem precisa ser processual e variada, para possibilitar aos educandos maneiras diferentes de apreender o conteúdo teórico e a prática de enfermagem: [...] um método avaliativo legal pra uma disciplina é você mesclar diferentes instrumentos de avaliação, a prova escrita, uma prova oral de repente, seminários, rodas de conversa, não sei, estudos dirigidos, portfólio reflexivo (Professor 5).[...]sempre intercalo muito os meios de avaliação, a minha perspectiva é mais formativa do que somativa, o estudo dirigido, eu amo rodas de conversa, faço muito com eles, júri simulado[...] (Professor 7).

Nessa mesma perspectiva, a Professora 8 declara que realiza a avaliação considerando as diferenças e as características de cada educando, seus variados modos de perceber o mundo. Assim, ela utiliza várias técnicas, como: [...] nós 
analisamos tais conteúdos a serem abordados e a gente vai fazer tipo um bingo, um passa e repassa [...] eu uso também entrega de artigos [...] eu faço teatro, [...] confeccionamos cartazes, a gente faz visita técnica, seminário [...].

Já, outros professores, avaliam "o produto", ou seja, observam se a conduta do estudante no cenário da prática contribuiu para a mudança do serviço de saúde: [...] quando um aluno ou educando chega lá no serviço de saúde comigo, e ai que se observa se ele avançou, tem que ter uma avaliação de produto (Professor 9). Ela considera a avaliação como processo, reconhecendo avanços ou retrocessos, a medida em que a transformação do educando também ocorre e se projeta na mudança das suas atitudes.

\section{DISCUSSÃO}

Observa-se que as estratégias pedagógicas utilizadas pelos enfermeiros professores apresentam um processo de transição de práticas conservadoras para práticas libertadoras. ${ }^{1}$ Eles se preocupam em fundamentar-se em métodos variados para auxiliar a aprendizagem dos educandos. Estes caracterizam-se pela preocupação com a criticidade e com a autonomia do estudante e consideram a sua integração ao cenário da prática, sobretudo no âmbito da rede de atenção à saúde, ordenada pelo SUS.

Assim também são os processos avaliativos, em que são utilizados outros recursos que não somente "a prova". Eles ocorrem de maneira processual, imbricando teoria e prática, estudo e intervenção, considerando as características e o contexto de cada estudante.

Essa perspectiva realça a formação como dispositivo de coprodução de instituições e de sujeitos. Compreende-se que, ao optar por uma estratégia ou método educativo, se está assumindo uma tendência pedagógica de ensino, mesmo que de forma inconsciente. ${ }^{10} \mathrm{~A}$ tendência pedagógica utilizada pelos enfermeiros professores revela uma inclinação para a prática construtivista/libertadora que visa o estímulo da governabilidade da vida enquanto estudante e depois, na qualidade de profissional de saúde. ${ }^{1,6}$ 
$\mathrm{Na}$ contemporaneidade, demanda-se enfermeiros críticos e autocríticos, reflexivos, preparados para o trabalho em equipe e que exerçam com autonomia sua profissão. ${ }^{4,12}$ Essa tendência requer estratégias que estimulem a aproximação entre teoria e prática, assim as metodologias mais ativas (ou problematizadoras) ganham destaque, pois são utilizadas pelo docente como uma tentativa de aproximar os conteúdos teóricos e a realidade social, além de motivar os educandos a tecerem novas redes de conhecimentos. ${ }^{12-14}$

As metodologias problematizadoras estão alicerçadas ao princípio teórico da autonomia, defendido pelo educador Paulo Freire. ${ }^{1,6}$ Elas se fundamentam no desenvolvimento de habilidades para resolver problemas, valorizando o "saber-ser" e não somente o "saber-fazer". Enfrentar situações de imprevisibilidade e as mobilizações da inteligência para fazer face aos desafios do trabalho são características dessa tendência, a qual tem sido muito utilizada em cursos de graduação na área da saúde e de enfermagem que preocupam-se com a qualificação do futuro profissional para atuar no âmbito do SUS. ${ }^{14,15}$

Nota-se a preocupação dos participantes em propor um processo ensinoaprendizagem que pressuponha o respeito e a valorização da bagagem cultural do educando, bem como aos seus saberes construídos no processo de viver. Tal propósito só é possível, quando o educador tem humildade, se reconhece como ser inconcluso, considera os limites de seu conhecimento; e percebe o ganho substantivo advindo da sua interação com o educando. Essa atitude pedagógica implica na amorosidade ${ }^{1,6,11}$, sentimento que acompanha - ou deve acompanhar todo o itinerário formativo. Pressupõe também, por parte de ambos - professor e estudante - o envolvimento com a profissão escolhida, neste caso, a enfermagem e a docência.

Nessa direção, cumpre destacar que o educando sente-se valorizado quando o educador inicia a aula resgatando conceitos que são comuns a ele e que, portanto, fazem mais sentido em sua vida. As noções de diálogo podem contribuir para processos de interação na relação pedagógica - educador e educando - em que ambos aprendem juntos. ${ }^{1,6,16}$ Quando há uma relação nesse nível, e natural a existência de conflitos, o que dificulta um envolvimento - cuja alteridade é 
indiscutível - e por isso, o reconhecimento e compreensão dos diferentes pontos de vista e necessidades com base no diálogo e fundamental. ${ }^{17}$

Com esse propósito, a avaliação inovadora deve se comprometer com essa tendência da formação. Para tanto, é preciso um trabalho planejado e executado com a participação de todos os envolvidos. No presente estudo, nota-se que os registros, a auto-avaliação e o diálogo têm sido utilizados como estratégias norteadoras do processo. Qualquer iniciativa de inovação de práticas pedagógicas deve levar em conta as estratégias de avaliação, integrá-las à reflexão, para transformar a realidade. A avaliação precisa ser, antes de tudo, "processual e formativa para a inclusão, autonomia, diálogo e reflexões coletivas, na busca de respostas e caminhos para os problemas detectados". Dessa forma, não pune, nem estigmatiza, mas oferece diretrizes para se tomar decisões e definir prioridades..$^{13: 138}$

A presença de modelos pedagógicos tradicionais e tecnicistas na orientação do ensino em enfermagem são considerados burocráticos e pouco significativos para o educando. $O$ rompimento desses modelos implica em refletir e ter clareza sobre o momento histórico e social em que vivemos e sobre os paradigmas contemporâneos que propiciam o ajustamento da prática educativa, ampliando e transformando a dimensão técnica de ensinar. ${ }^{2}$ Mediante essas novas metodologias, aliadas a cenários de produção pedagógica diferenciados, acredita-se que será possível provocar mudanças no paradigma hegemônico, com vistas à reorientação dos modelos de atenção e da produção de saúde. ${ }^{18}$ De maneira convergente com tais recomendações, a integração entre teoria e prática, determinadora da práxis, opera como possibilidade transformadora da realidade..$^{1,6}$

$\mathrm{Na}$ ótica do referencial de "aprender a aprender" ${ }^{14}$ as DCN preveem a atenção à saúde coerente com o princípio da integralidade, a tomada de decisões, a comunicação, a liderança, o gerenciamento e a educação permanente como competências gerais na formação dos profissionais de saúde. ${ }^{4}$ Soma-se a isso a formação direcionada ao contexto real, evidenciando que as fronteiras entre ensino e serviço estão imbricadas entre si, como potências de construção do saber e da cidadania. Trata-se da integração ensino-serviço, pressuposto fundamental para o itinerário formativo na área da saúde na contemporaneidade, pois favorece o diálogo entre todos os atores: professores e educandos, na academia; estes com os 
profissionais e gestores, no serviço; e de todos com a comunidade, nos mais diversos territórios; fazendo esse movimento refletir na qualidade da atenção à saúde, como se fosse um prisma que, ao receber a luz branca, a reflete de forma multicolorida. ${ }^{17}$

$\mathrm{Na}$ perspectiva da integracao ensino-servico, o espaço pedagógico não se esgota na sala de aula, mas implica a vivência no mundo do trabalho, com seus diferentes cenários de práticas, repletos de experiências de aprendizagem. Este precisa ser construído pedagogicamente, de acordo com a interposição críticocriativa dos envolvidos ${ }^{19}$. E dessa maneira que se torna possível a integração entre teoria e prática, colocando-se a serviço da reflexão e transformação da realidade, ou seja, da práxis ${ }^{6,19}$. A partir desses elementos, cria-se a educação problematizadora que implica no esforço permanente pelo qual os sujeitos se percebem criticamente no mundo, buscando soluções e comprometendo-se com a resolução dos problemas $^{1,20}$.

A formação de profissionais com perspectiva inovadora e abordagem críticoreflexiva é uma das maneiras de transformar o modelo de atenção vigente, na direção do SUS. ${ }^{14}$ Assim como, a inserção do estudante na realidade dos trabalhadores possibilita a formação de profissionais preparados para atuar nessa perspectiva, em consonância com os objetivos da Atenção Primaria, dentre os quais, a humanização da assistência, a ênfase na promoção da saúde, a assistência domiciliar e alta resolutividade.

As escolas de enfermagem estão gradativamente, assumindo o desafio de elaborar metodologias pedagógicas e estruturas curriculares coesas com as DCNs. Assim, vale destacar que as DCNs atuam como um guia, um caminho para as escolas estruturarem coletivamente e de acordo com a realidade local o seu Projeto Político Pedagógico e a partir das suas próprias estratégias pedagógicas. ${ }^{21} \mathrm{O}$ papel do enfermeiro professor, nesse contexto é o de facilitador do processo, apoiador, desenvolvendo um modo de agir interativo com os estudantes, numa rede de saber/fazer. ${ }^{10}$ Entretanto, os dados mostram que, tal como em outros estudos, ${ }^{22} \mathrm{o}$ educador, por vezes, associa sua atuação como docente com o processo educacional que vivenciou durante a sua própria formação, utilizando as mesmas práticas pedagógicas que regiram o seu itinerário formativo, durante a permanência 
como estudante. Assim, considera-se necessário que o enfermeiro busque, de maneira contínua, aprimoramento para o desempenho das habilidades do ser professor, não só no âmbito da graduação e da pós-graduação em enfermagem, mas nos demais contextos em que essa profissão demanda da sua atuação como educador.

\section{CONCLUSÕES}

As percepções dos coordenadores dos professores e estudantes sobre as estratégias pedagógicas e avaliativas, na maior parte das vezes, se aproximam ou tangenciam os pressupostos políticos que operam à luz da obra textual do educador Paulo Freire. Isso se revela na atitude dos docentes enfermeiros, mediante seus discursos, os quais estão gradativamente, assumindo a tendência pedagógica libertadora. São identificadas no seu processo de ensinar estratégias distintas, voltadas a realidade do educando, e preocupação com esse ser em formação e com o seu aprendizado, de maneira processual e centrada em suas vivencias praticas, como um ser cultural, que constrói e assume atitude crítica perante a história. Nessa perspectiva, consideram ineficazes as estratégias avaliativas tradicionais, pontuais e que não implicam na evolução do educando. Busca-se uma formação para a vida, para o aprender a aprender, para lidar com os conflitos do dia-a-dia e com a realidade dos serviços de saúde.

O estudo reforça a perspectiva de que a rede de atenção à saúde, como cenário das atividades teórico-práticas e estágios, é componente essencial para vivência do que significa ser enfermeiro. Isso implica na constante integração entre o ensino e o serviço em saúde.

Frente a isso, observou-se que as estratégias pedagógicas que norteiam as práticas dos enfermeiros professores nas instituições estudadas, estimulam o diálogo, a formação de sujeitos críticos, autocríticos e reflexivos, a libertação e não a domesticação. O processo avaliativo, via de regra, ocorre de maneira processual e segue a mesma tendência, gradativamente.

Assim, salienta-se a necessidade de que, na formação em enfermagem, como em outras da saúde, educador e educando sejam sujeitos de sua prática, 
criando-a e recriando-a por meio da ação-reflexão-ação sobre o cotidiano, na lógica da pedagogia crítica/libertadora defendida por Paulo Freire.

\section{REFERENCIAS}

1. Freire P. Pedagogia do oprimido. 59a ed. Rio de Janeiro: Paz e Terra; 2015.

2. Lima MML, Reibnitz KS, Prado ML, Kloh D. Comprehensiveness as a pedagogical principle in nursing education. Texto Contexto Enferm.2013[citado em 2016 abr 04]; 22(1):106-13. Disponível

em:

http://www.scielo.br/scielo.php?script=sci arttext\&pid=S0104-07072013000100013.

3. Freire P. Educação e mudança. 24. ed. São Paulo: Paz e Terra; 2001.p 148.

4. Brasil. Ministério da Educação. Resolução CNE/CES no 3, de 7 de novembro de 2001. Institui Diretrizes Curriculares Nacionais do Curso de Graduação em Enfermagem. Diário Oficial da União, Brasília (DF); 9 nov 2001.

5. Rodriguez-García M, Medina-Moya JL. The legacy of care as reflexive learning. Rev. Latino-Am. Enfermagem.2016[Citado em 2016 jan 20];24:e2711.Disponível em: http://www.scielo.br/pdf/rlae/v24/pt 0104-1169-rlae-24-02711.pdf.

6. Freire P. Pedagogia da autonomia: saberes necessários à prática educativa. São Paulo: Paz e Terra; 2011.

7. Bakes DS, Marinho M, Costenaro RS, Nunes S, Rupolo I. Repensando o ser enfermeiro professor na perspectiva do pensamento complexo. Rev Bras Enferm. 2010 [citado em 2016 abr 04];63(3):421-6. Disponível em: http://www.scielo.br/scielo.php?script=sci_arttext\&pid=S0034-71672010000300012.

8. Friedrich DBC, Gonçalves AMC, Sá TS, Sanglard LR, Duque DR, Oliveira GMA. O portfólio como avaliação: análise de sua utilização na graduação de enfermagem. Rev Latino-Am Enferm. 2010 [citado em 2016 abr 04];18(6):1123-30. Disponível em: http://www.scielo.br/pdf/rlae/v18n6/pt_12.pdf

9. Minayo MCS. O desafio do conhecimento: pesquisa qualitativa em saúde. $14^{\mathrm{a}} \mathrm{ed}$. São Paulo: Hucitec; 2014.

10. Ceccim RB, Ferla AA. Abertura de um eixo reflexivo para a educação da saúde: o ensino e o trabalho. In: Marins JJN, Rego S. Educação Médica: gestão, cuidado e avaliação. São Paulo: Hucitec; 2011. p.258-77. 
11. Lazzari DD, Pedro ENR, Sanches MO, Jung W. Estratégias de ensino do cuidado em enfermagem: um olhar sobre as tendências pedagógicas. Rev Gaúcha Enferm. 2011 [citado em 2016 mar 10]; 32(4): 688-94. Disponível em: http://www.scielo.br/scielo.php?script=sci_arttext\&pid=S1983-14472011000400008.

12. Rodrigues JA, Rocha LS, Anjos DS, Cavalcante LPF, Rozendo CA. Pedagogical trends: conflicts, challenges and perspectives of nursing teachers. Rev Bras Educ Med. 2013 [citado em 2016 mar 08];37(3):333-49. Disponível em: http://www.scielo.br/scielo.php?script=sci_arttext\&pid=S0100-55022013000300005.

13. Mitre SM, Siqueira-Batista R, Girardi-de-Mendonça JM, Morais-Pinto NM, Meirelles $C A B$, Pinto-Porto $C$, et al. Metodologias ativas de ensino-aprendizagem na formação profissional em saúde: debates atuais. Cienc Saúde Coletiva. 2008 [citado em 2016 mar 08];13(2):2133-144. Disponível em: http://dx.doi.org/10.1590/S141381232008000900018.

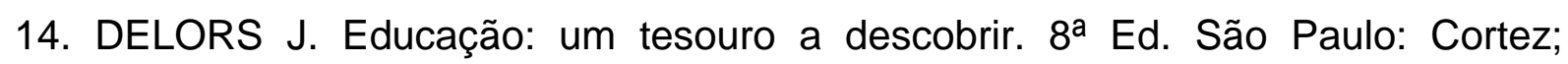
Brasília, DF: MEC: UNESCO; 2003.

15. Vendruscolo C, Kleba ME, Krauzer IM, Hillesheim A. Planejamento situacional na Estratégia Saúde da Família: atividade de integração ensino-serviço na enfermagem. Rev Gaúcha Enferm. 2010 [citado em 2016 jan 25];31(1):183-6. Disponível em: http://dx.doi.org/10.1590/S1983-14472010000100026.

16. Freire $P$, Faundez A. Por uma pedagogia da Pergunta. $7^{\mathrm{a}}$ ed. Rio de janeiro: Paz e Terra; 2011.

17. Vendruscolo C, Ferraz F, Prado ML, Kleba ME. Teaching-service integration and its interface in the context of reorienting health education. Interface (Botucatu) [online]. 2016 jun; 20(59):1015-1025. Disponivel em:http://dx.doi.org/10.1590/180757622015.0768 .

18. Ferraz F, Vendruscolo C, Kleba M, Prado M, Reibinitz K. Ações Estruturantes Interministeriais para Reorientação da Atenção Básica em Saúde: convergência entre educação e humanização. O Mundo da Saúde 2012 [citado em 2016 jan 25]; 36(3):482-93.

Disponível

em:

http://bvsms.saude.gov.br/bvs/artigos/mundo_saude/acoes_estruturantes_interminist eriais_reorientacao_atencao.pdf. 
19. Reibnitz KS, Prado ML. Inovação e Educação em Enfermagem. Florianópolis: Cidade Futura; 2006.

20. Freire P. Conscientização: teoria e prática da libertação: uma introdução ao pensamento de Paulo Freire. 3a ed. São Paulo: Centauro; 2001.

21. Kloh D, Reibnitz KS, Boehs AE, Wosny AM, Lima MM. Princípio da integralidade do cuidado nos projetos político-pedagógicos dos cursos de Enfermagem. Rev Latino-Am Enferm. 2014 [citado em 2015 dez 20];22(4):01-8. Disponível em: http://www.scielo.br/pdf/rlae/2014nahead/pt_0104-1169-rlae-0104-1169-33812469.pdf.

22. Gubert E, Prado ML. Desafios na prática pedagógica na educação profissional em enfermagem. Rev Eletrônica Enferm. 2011[citado em 2016 jan. 02];13(2).

Disponível em: http://www.fen.ufg.br/revista/v13/n2/v13n2a15.htm. 